\title{
Editorial: Modelling, Simulating and Forecasting Regional Climate and Weather
}

\author{
Hans von Storch ${ }^{1 *}$, Frauke Feser ${ }^{1}$, Rene Laprise ${ }^{2}$, Martin Stendel $^{3}$ and Izuru Takayabu ${ }^{4}$ \\ ${ }^{1}$ Helmholtz Centre for Materials and Coastal Research (HZG), Geesthacht, Germany, ${ }^{2}$ Department of Earth and Atmospheric \\ Sciences, Université du Québec à Montréal, Montreal, QC, Canada, ${ }^{3}$ Danish Meteorological Institute, Copenhagen, \\ Denmark, ${ }^{4}$ Department of Climate and Geochemistry Research, Meteorological Research Institute, Tsukuba, Japan
}

Keywords: modeling, simulating, forecasting, climate, weather

\section{Editorial on the Research Topic}

\section{Modelling, Simulating and Forecasting Regional Climate and Weather}

Originally, climatology was a regional science (von Storch, 1999)—and the global climate merely something put together from the real and challenging findings-the regional climate analyses. Also, weather forecasting was mostly considered a process, which was made possible by regional information, and was of interest only for a regional audience. This has massively changed since, say, the 1960s, when systems for assembling observations from all corners of the globe were set up, and when global atmospheric models appeared as the dynamically right way to describe the circulation of the atmosphere. Thus, the global view became the dominant one in climatology, and in forecasting.

However, a niche remains for the regional set-up. First, the regional model can provide much more spatial detail than a global model, given the same computer power. Historically, this was in particular of importance, when the issue was the regional manifestation, say in terms of precipitation, of a given circulation-in the spirit of Starr's (1942) two-step concept of forecasting-first the large scale-circulation, then the regional or local manifestation.

Initially the regional set-up was challenged by the fact that the boundary-initial value problem for the equations of motion for limited areas is not well posed-among others, there may be several solutions satisfying the boundary values. Also, the propagation of disturbances on the finite grid may be different from the observed propagation; when data from a coarser resolution global model is used, the same problem emerges. This was solved by a rather practical way with the "sponge-zone," suggested by Davies (1976).

For a long time, regional climate models were something like all-purpose tools, and little attention was paid to the question, what specific added value its usage would provide, apart from a general "greater spatial detail"-claim. This greater spatial detail was in particular useful for hydrological applications, and early efforts dealt with coupling of these components. At the same time, global modeling focused on coupling with the oceanic dynamics, and the sea ice dynamics. Obviously, these two components are also crucial for the skill of regional climate change. However, the efforts to extend atmospheric limited area models in this way, commenced seriously only in the last 10, or so, years (e.g., Ham et al., 2016). What was also overseen in the climate applications was the presence of unprovoked variability, sometimes named noise, which lead to intermittent divergence in phase space (Weisse et al., 2000), and which made a statistical evaluation of numerical experiments with regional models necessary, as was recognized by global modelers already in the 1970s. This need is still not recognized generally. 
This was the background of the editors for suggesting a volume of Modeling, Simulating and Forecasting Regional Climate and Weather. We wanted to push for further advanced but critical efforts on the different usages of limited area models-and we made some progress, albeit more work needs to be done.

The skill of regional climate models in providing useful atmospheric states for studying climate impacts is one aspect of our collection of papers:

- One case (Feng T. et al.) deals with extreme dry spells in Southwest China. A series of regional climate models was found capturing the intensity and duration of such events reasonably well. Also, the statistics of the maximum dry spell length would be reproduced properly. The authors concluded "This information is useful for model evaluation and improvement, future climate projections, and water resource risk management."

- Prein et al. look at the ability of regional models to simulate 12 hydrologically important weather types (WTs) in the contiguous United States. When interested in localized hydrological processes, it is important to get these weather types right, which the authors enforced by constraining the regional model to stay close to the large-scale state of the driving global analysis ("spectral nudging"). In this set-up they found that the choice of parametrizations and grid resolution had little effect-given the constraining. Instead they found it crucial to select global simulations with realistic synopticscale variability.

- The biophysical effect of de- and afforestation in Europe, conditional upon different parameterizations of albedo is examined. Afforestation was found to be a warming in winter (Tölle et al.). However, the net effect in summer was small because of canceling albedo and evapotranspiration effects. The summer temperature change is strongly sensitive to the albedo parameterization, which needs to account for different vegetation types.

- Bit outside of the scope of collection of papers is the article by Rath and Costa-Cabral, who constructed an advanced, cointegration-based forecast scheme for snowpack for the Eastern Sierra Nevada.

Regional models are often used for constructing high-resolution scenarios of climate change conditional upon a global climate change projection.

- Matte et al. analyzed "European seasonal temperature and precipitation climate change projections using pan-European regional climate model projections for the twenty-first

\section{REFERENCES}

Davies, H. C. (1976). A lateral boundary formulation for multi-level prediction models. Q. J. R. Meteorol. Soc. 102, 405-418. doi: 10.1256/smsqj. 43209

Ham, S., Yoshimura, K., and Li, H. (2016). Historical dynamical downscaling for East Asia with the atmosphere and ocean coupled century." They find that "[e]mploying a simple scaling with the global mean temperature change enables the identification of emerging robust signals of seasonal changes." Additionally, they study the climate change signals from transient experiments at the time of an emerging global temperature exceedance of e.g., 1,2 , or $3^{\circ} \mathrm{C}$.

- Feng J. et al. deal with the issue of localized changes in the expected storm surge heights at 15 Chinese sites by combining local observed statistics and scenarios of mean sea level rise provided by global climate change scenarios.

Another class of applications dealt with using regional models in process studies, mostly hydrological process studies:

- Eghdami and Barros study Cold Air Intrusions (CAIs) along the eastern flanks of the tropical Andes. They found "significant precipitation enhancement from intense shallow convection at the CAI frontal boundary amplified by orographic lifting as it propagates northward latched to the slopes of Andes."

- Wang et al. have looked at the significance of initial soil moisture (ISM) conditions on the simulation of three severe heat wave events in eastern China. They found a positive feedback between atmospheric circulation, surface warming, and soil dryness, when the ISM is reduced-it "locally strengthens the surface warming and the further drying of the soil. .... The reduced ISM forces positive anomalies of geopotential height at mid-troposphere and negative anomalies at lower levels, leading to an enhanced thickness of the atmosphere."

- The question how an extreme precipitation event at Hiroshima in 2014 would unfold under climate change conditions was studied by Hibino et al. using a $500 \mathrm{~m}$-grid resolution model. The main result is that the "effect of the water vapor increase on extreme precipitation is canceled out by the suppression of convection due to the thermal stability enhancement" so that the expected change is small.

A conceptual look at the downscaling paradigm, and its roots-synoptic dynamics and spatial interpolation-was done by von Storch and Zorita. Even if here the concept and history of the empirical variant of downscaling was discussed, these deliberations apply to the dynamical variant as well.

\section{AUTHOR CONTRIBUTIONS}

All authors listed have made a substantial, direct and intellectual contribution to the work, and approved it for publication.

regional model. J. Meteorol. Soc. Jpn. 94, 199-208. doi: 10.2151/jmsj.20 15-046

Starr, V. P. (1942). Basic Principles of Weather Forecasting. New York, NY; London: Harper Brothers Publishers, 299.

von Storch, H. (1999). “The global and regional climate system," in Anthropogenic Climate Change, eds H. von Storch and G. Flöse (Heidelberg: Springer Verlag), $3-36$. 
Weisse, R., Heyen, H., and von Storch, H. (2000). Sensitivity of a regional atmospheric model to a sea state dependent roughness and the need of ensemble calculations. Mon. Weather Rev. 128, 3631-3642. doi: 10.1175/15200493(2000)128<3631:SOARAM>2.0.CO;2

Conflict of Interest: The authors declare that the research was conducted in the absence of any commercial or financial relationships that could be construed as a potential conflict of interest.
Copyright (C) 2020 von Storch, Feser, Laprise, Stendel and Takayabu. This is an open-access article distributed under the terms of the Creative Commons Attribution License (CC BY). The use, distribution or reproduction in other forums is permitted, provided the original author(s) and the copyright owner(s) are credited and that the original publication in this journal is cited, in accordance with accepted academic practice. No use, distribution or reproduction is permitted which does not comply with these terms. 